\title{
Assemblages and Distributions of Groundfish Species off the West Coast of Vancouver Island
}

\author{
Matthew George Bryan*, Caihong Fu and Greg D. Workman \\ Pacific Biological Station, Fisheries and Oceans Canada, 3190 Hammond Bay Road, Nanaimo BC, V9T 6N7, Canada
}

\begin{abstract}
Fluctuations in environmental conditions have been shown to alter the productivity of the marine ecosystem off the west coast of Vancouver Island, but it is unclear how individual groundfish species respond to changing seas, in part because the distributions of these species along environmental gradients are unknown. The recent global declines in stock biomass, biodiversity, and mean trophic level of landings have led to proposals for ecosystem-based fisheries management. Before such a system could be implemented, it would be necessary to identify the species assemblages that would define management areas. By analysing catch data from biennial research trawls conducted 2004-2008, with oceanographic data from the same region we attempted to determine the distributions of the 38 species that comprise the top $95 \%$ of the biomass and to identify any natural assemblages that may be present. Neither an Average Bray-Curtis dendrogram nor a Canonical Analysis produced any realistic assemblages, though a Canonical Correspondence Analysis identified the two major factors in determining species identity as surface chlorophyll concentration and depth. We examined species richness, finding that it also increased with depth, though this may be an artefact of the sampling gear used, which targets larger bodied species. We conclude by questioning the validity and value of assigning species to discrete assemblages when species identity appears to vary continuously along environmental gradients and by discussing potential problems with assemblage-based fisheries management.
\end{abstract}

Keywords: Fish assemblage, bottom trawling, marine fisheries, environmental conditions, benthic communities, multivariate analysis, northeast pacific ocean, vancouver island.

\section{INTRODUCTION}

Many fisheries are managed with the goal of maintaining a single stock at a sustainable optimum population level, ignoring the idea that fluctuations in environmental conditions will likely be reflected in population sizes of target fish species [1]. It is apparent that localized environmental variation produces changes in the level of primary production [1], and that primary production is a major determinant of overall biomass [2]; therefore, it follows that environmental characteristics may play an important role in determining the abundance, biomass, and distribution of fish species, but the specific details of these species-environment interactions remain unclear. Some fish species appear to directly respond to changing environmental conditions $[3,4]$; however, we are not aware of any studies that have determined such relationships for the species off the West Coast of Vancouver Island at this time. With the potential for climate change to drastically alter oceanographic conditions $[5,6]$, we must know how individual species will respond if we hope to successfully manage fish stocks. To learn this, we must first determine the current environmental distributions of individual species to serve as a baseline for future studies and to allow predictions as to how distributions may be altered by changing seas.

In addition to preparing for the effects of climate change, fisheries must respond to global reductions in stock biomass and biodiversity [7], as well as decreases in the mean trophic level of most landings [8]. Ecosystem-based fisheries management has been proposed as a potential improvement

*Address correspondence to this author at the 1925 Townley Street, Victoria, BC, V8R 3B1, Canada; E-mail: mgbryan@uvic.ca over single stock management [8-11]. For such a system to be effective there would need to be an understanding of the community structure of the ecosystems being targeted $[9,10,12]$. With the high number of species caught in most trawls, it would be helpful to have a way of narrowing down potential interspecies interactions. Determining species assemblages is a valuable step, as it provides the means to identify species that frequently co-occur and may possibly interact. It is also possible to examine the distribution of species assemblages along environmental gradients to determine which oceanographic characteristics are important in separating assemblages $[4,13,14]$. Assemblages with narrow distributions (e.g. strict niche requirements) may identify regions that could be considered as essential fish habitat [15], and should probably be managed more cautiously than assemblages with wide distributions. Determining the environmental needs of species assemblages may also provide insight into how species will respond to changing oceanographic conditions [16]. One caveat in determining assemblages is the assumption that the species are distributed in natural groupings with clear separation between them; this assumption and how to deal with deviations from it are major points of discussion in the assemblage research literature $[6,17,18]$.

Using data from biennial groundfish research trawls conducted off the west coast of Vancouver Island from 2004-2008, we attempt in this paper to determine the assemblages of the most prevalently caught fish species and relate these assemblages to environmental gradients. We also examine how environmental gradients affect the species diversity, richness, and dominance at each trawl location. We conclude by questioning the rationale and efficacy of forcing 


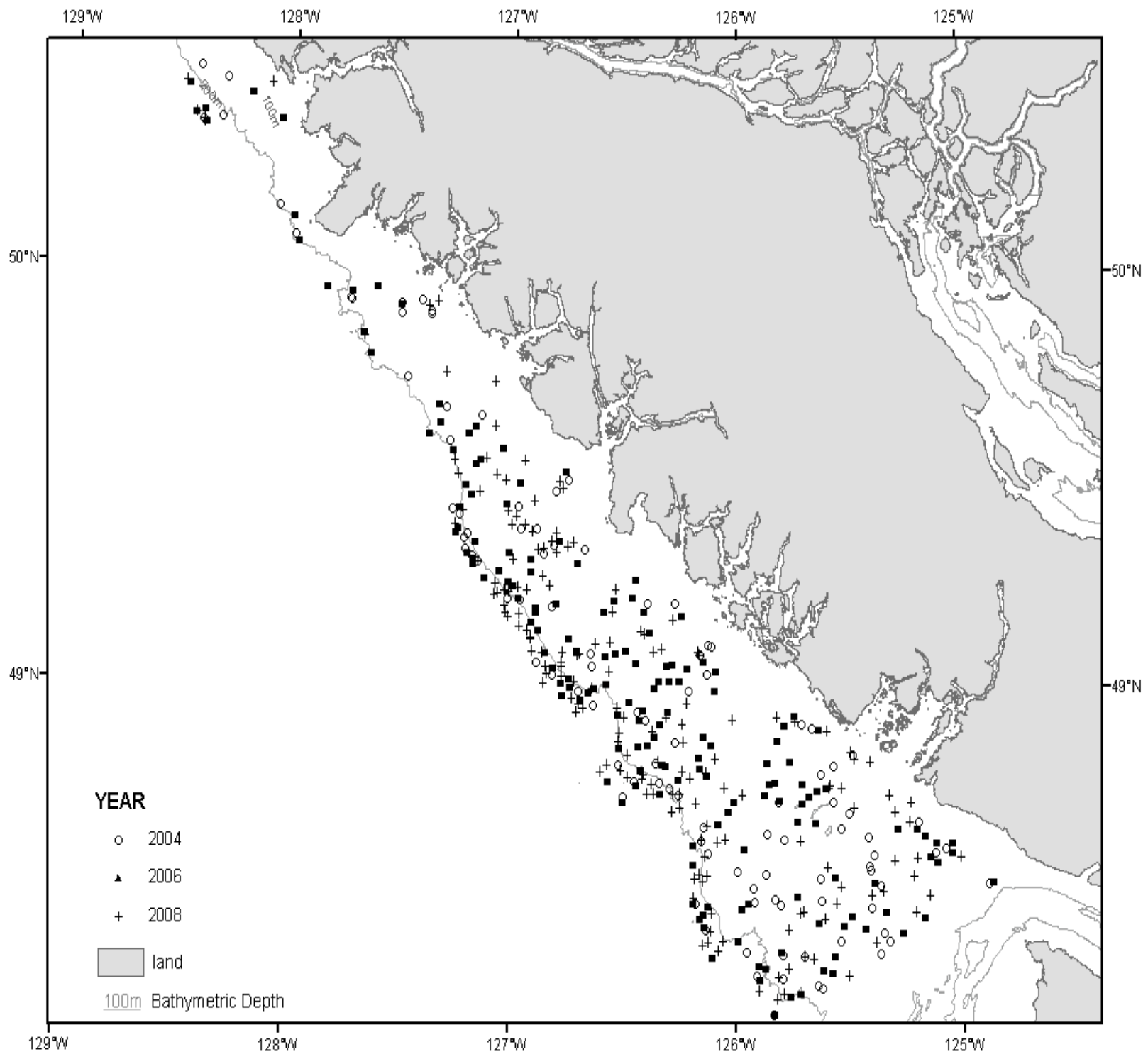

Fig. (1). Locations of the trawls conducted each year.

species into discrete assemblages if species composition actually varies continuously along environmental gradients and by suggesting a new management system based on species distributions and designed to maximize the catch to bycatch ratio of trawls, thereby minimizing environmental impacts while maintaining yields of target species.

\section{MATERIALS AND METHODOLOGY}

The synoptic, random depth-stratified groundfish survey off the west coast of Vancouver Island has been conducted in three years: 2004, 2006, and 2008 (Fig. (1); for a detailed description of survey methods see [19]). For each trawl, the weight of each species was recorded, as were vessel position (latitude and longitude), trawl distance, day and time of trawl, vessel speed, trawl depth, and water characteristics at net depth (temperature, salinity, and dissolved oxygen concentration). Salinity and dissolved oxygen concentration measurements were not taken in 2004. Data were retrieved from the GFBio database stored at the Pacific Biological Station in Nanaimo, BC.
The research catch data contained many infrequently occurring species. To simplify analysis, the data were reduced to those for 38 species, selected on the basis of their comprising the top $95 \%$ of the total biomass caught and their appearance in a high number of trawls (Table 1). Catch weight was standardized by the recorded trawl distance to generate catch per unit effort (CPUE) values. If trawl distance was missing from the data, distance was calculated based on the Great Circle Distance Formula (GCDF) using the trawl start and end location, recorded in decimal degrees:

$$
\begin{aligned}
& 3437.74677 \times \arccos \left[\sin \left(\frac{\text { lat } 1}{57.2958}\right) \times \sin \left(\frac{\text { lat } 2}{57.2958}\right)+\cos \left(\frac{\text { lat } 1}{57.2958}\right)\right. \\
& \left.\times \cos \left(\frac{\text { lat } 2}{57.2958}\right) \times \cos \left(\frac{\text { lon } 2}{57.2958}-\frac{\text { lon } 1}{57.2958}\right)\right]
\end{aligned}
$$

where 3437.74677 is the radius of the Earth in nautical miles, 57.2958 is the approximation of $180 / \pi$, lat 1 , lat 2 , lon 1 , and lon 2 are the starting and ending latitude and 
Table 1. Species Comprising the Top 95\% of the Biomass and Appearing in the Majority of Trawls. Instances: Number of Trawls in which the Species Appeared

\begin{tabular}{|c|c|c|c|}
\hline Species Common Name & Scientific Name & Total Catch (Kg) & Instances \\
\hline Arrowtooth Flounder & Atheresthes stomias & 53261.93 & 364 \\
\hline Big Skate & Raja binoculata & 565.61 & 32 \\
\hline Bigfin Eelpout & Lycodes cortezianus & 105.57 & 67 \\
\hline Black Eelpout & Lycodes diapterus & 26.15 & 31 \\
\hline Blackbelly Eelpout & Lycodes pacificus & 55.74 & 69 \\
\hline Bocaccio & Sebastes paucispinis & 1285.39 & 87 \\
\hline Canary Rockfish & Sebastes pinniger & 10749.28 & 147 \\
\hline Darkblotched Rockfish & Sebastes entomelas & 973.10 & 91 \\
\hline Dover Sole & Microstomus pacificus & 13788.48 & 371 \\
\hline English Sole & Paroprys vetulus & 3965.24 & 261 \\
\hline Eulachon & Thaleichthys pacificus & 708.55 & 88 \\
\hline Flathead Sole & Hippoglossoides elassodon & 1353.27 & 139 \\
\hline Greenstriped Rockfish & Sebastes elongatus & 3576.12 & 200 \\
\hline Lingcod & Ophiodon elongatus & 6048.79 & 252 \\
\hline Longnose Skate & Raja rhina & 3142.30 & 236 \\
\hline Pacific Cod & Gadus macrocephalus & 3453.15 & 213 \\
\hline Pacific Hake & Merluccius productus & 3697.86 & 151 \\
\hline Pacific Halibut & Hippoglossus stenolepis & 3421.72 & 212 \\
\hline Pacific Herring & Clupea pallasi & 77.99 & 75 \\
\hline Pacific Ocean Perch & Sebastes alutus & 25315.48 & 160 \\
\hline Pacific Sanddab & Citharichthys sordidus & 2927.52 & 146 \\
\hline Petrale Sole & Eopsetta jordani & 1427.86 & 244 \\
\hline Pink Shrimp Smooth & Pandalus jordani & 69.00 & 58 \\
\hline Redbanded Rockfish & Sebastes babcocki & 1116.37 & 141 \\
\hline Redstripe Rockfish & Sebastes proriger & 7924.05 & 82 \\
\hline Rex Sole & Errex zachirus & 10411.39 & 395 \\
\hline Rougheye Rockfish & Sebastes aleutianus & 2470.24 & 83 \\
\hline Sablefish & Anoplopoma fimbria & 12557.54 & 237 \\
\hline Sandpaper Skate & Bathyraja interrupta & 83.24 & 58 \\
\hline Sharpchin Rockfish & Sebastes zacentrus & 7928.83 & 131 \\
\hline Shortspine Thornyhead & Sebastolobus alascanus & 2324.80 & 118 \\
\hline Silvergrey Rockfish & Sebastes brevispinis & 3088.97 & 112 \\
\hline Slender Sole & Lyopsetta exilis & 698.96 & 269 \\
\hline Spiny Dogfish & Squalus acanthias & 60788.02 & 347 \\
\hline Splitnose Rockfish & Sebastes diploproa & 13926.23 & 101 \\
\hline Spotted Ratfish & Hydrolagus colliei & 6446.22 & 368 \\
\hline Walleye Pollock & Theragra fucensis & 486.57 & 49 \\
\hline Yellowtail Rockfish & Sebastes flavidus & 12039.93 & 153 \\
\hline
\end{tabular}

longitude respectively. The GCDF was not used for all trawls, as not all trawls had recorded start and end points. A $t$-test identified no difference in the mean distances calculated using the two separate methods. A two-way Analysis of Variance (ANOVA) was run to determine whether CPUE varied between years, and whether this effect 
was constant for all species. This and all further statistical analyses were performed using $\mathrm{R}$ [20], including the BiodiversityR [21] and Vegan [22] packages. Additional environmental variables we investigated were winter flow velocity (WinFlow) from the ROMS model (Mike Foreman, Institute of Ocean Sciences, pers. comm.) and surface chlorophyll concentration (Chloro), based on data from the MODIS sensor (Edward Gregr, unpublished data, SciTech Environmental Consulting, Vancouver, BC); however, no annual variations were available for these variables, so the value at each location represents an average across time. The correlation between environmental variables was explored using a scatterplot matrix and Principle Component Analysis (PCA).

The CPUE of each species in each trawl was plotted, using each species as an orthogonal axis. By viewing the resulting 38-dimensional space using GGobi [23] it was possible to identify any potential trends or species clustering [24]. The relationships between the species were examined using a Bray-Curtis similarity matrix [25] based on the CPUE data. The Average linkage method was used to produce a dendrogram for visual inspection of the results. A Canonical Analysis (CA) was run on the combined CPUE data from all years to look for co-occurring species. CA was selected over PCA because the species CPUE were distributed unimodally with respect to environmental gradients [24]. The dendrogram and the output of the CA were compared visually to identify any commonality in the groupings formed by the two methods.

The effects of individual environmental variables on the CPUE of each species were studied using boxplots. Canonical correspondence analysis (CCA) tests were run to examine the relationship between environmental variables and both untransformed and square-root transformed CPUE. CCA is a multivariate method for estimation and statistical testing of the effects of environmental variables and other explanatory variables on biological communities, potentially able to unravel how multiple species simultaneously respond to those environmental variables [26]. The square-root transformation was selected for its minimal data compression, which allows for dampening but not elimination of large values that may provide useful information [27]. Trawls without a measurement for an environmental variable were removed, so the CCA was run with the data from 296 trawls. Vessel speed was excluded from analysis because of large gaps in the data. Environmental variables with a high Variance Inflation Factor (VIF) were removed, and analyses were re-run. An ANOVA-like permutation test based on 1000 iterations was conducted after each run of the CCA to assess the significance of each of the environmental variables. A stepwise backwards procedure was followed to remove variables that were not significant $(\alpha=0.05)$ until only significant variables remained.

Community indices including species diversity, richness, and dominance were calculated and mapped to identify spatial trends. Species diversity was calculated based on the Shannon index, H':

$$
H^{\prime}=-\sum_{i=1}^{n} \frac{N_{i}}{N} \log \left(\frac{N_{i}}{N}\right)
$$

where $n$ is the total number of species, and $N_{i}$ and $N$ represent the CPUE of species $i$ and the sum of total $n$ species in that trawl. Each trawl was conducted with the same sampling effort, so the comparison of this index between the trawls is valid [28]. Species richness (S) was calculated as the number of species present in each trawl (from the reduced species list). Dominance was calculated as the Berger-Parker Dominance Index:

$$
d=p_{\max }=\frac{n_{\max }}{N}
$$

where $n_{\max }$ is the highest individual CPUE within a trawl, and $N$ is the total CPUE for each trawl. The dominant species was also identified in each trawl as the species with the highest CPUE. An ANOVA was run to examine the effects of depth and chlorophyll concentration on species richness.

\section{RESULTS}

Based on the ANOVA examining the effects of species identity and year on CPUE, the CPUE for all species was constant across the three sampled years, but there were significant differences between species (Table 2, Fig. 2). There was a minimal loss of information when the three years were pooled.

Table 2. ANOVA Results Showing that CPUE was Significantly Different between Species, but was Consistent between Years $(R 2=\mathbf{0 . 0 5 3 5 3})$

\begin{tabular}{|c|c|c|c|c|c|}
\hline & df & SS & MS & $\boldsymbol{F}$ & $\boldsymbol{P}$ \\
\hline \hline Species & 37 & 20131907 & 544106 & 8.4439 & $<2 \times 10^{-16}$ \\
\hline Year & 2 & 223288 & 111644 & 1.7326 & 0.1769 \\
\hline Species:Year & 74 & 3091996 & 41784 & 0.6484 & 0.9916 \\
\hline Residuals & 6434 & 414591178 & 64438 & & \\
\hline
\end{tabular}

The temperature, oxygen saturation, salinity, and chlorophyll variables were correlated with one another and with depth (Fig. 3, Table 3). There was also a strong correlation between the latitude and longitude variables due to the orientation of the island (Table 3). A PCA run on the environmental variables revealed a clear division between physical, biological, and chemical oceanographic variables along the first component axis, and physical and sampling variables along the second component axis, with strong correlation between the variables in each group (Fig. 4, Table 4).

In the 38-dimensional visualization, most trawls were clumped into a single dense cloud near the origin; however, the more distant points were not distributed into a hypersphere or hyperellipse, but rather appeared to extend into planes, following no discernable pattern. The Average Bray-Curtis clustering (Fig. 5) and the Canonical Analysis (Fig. 6) identified the same grouping of rockfishes. In general, there was minimal similarity in the relationships determined by the two methods (e.g. compare the relationship between Big Skate and Walleye Pollock, or the relative position of Spiny Dogfish). Dividing the dendrogram 


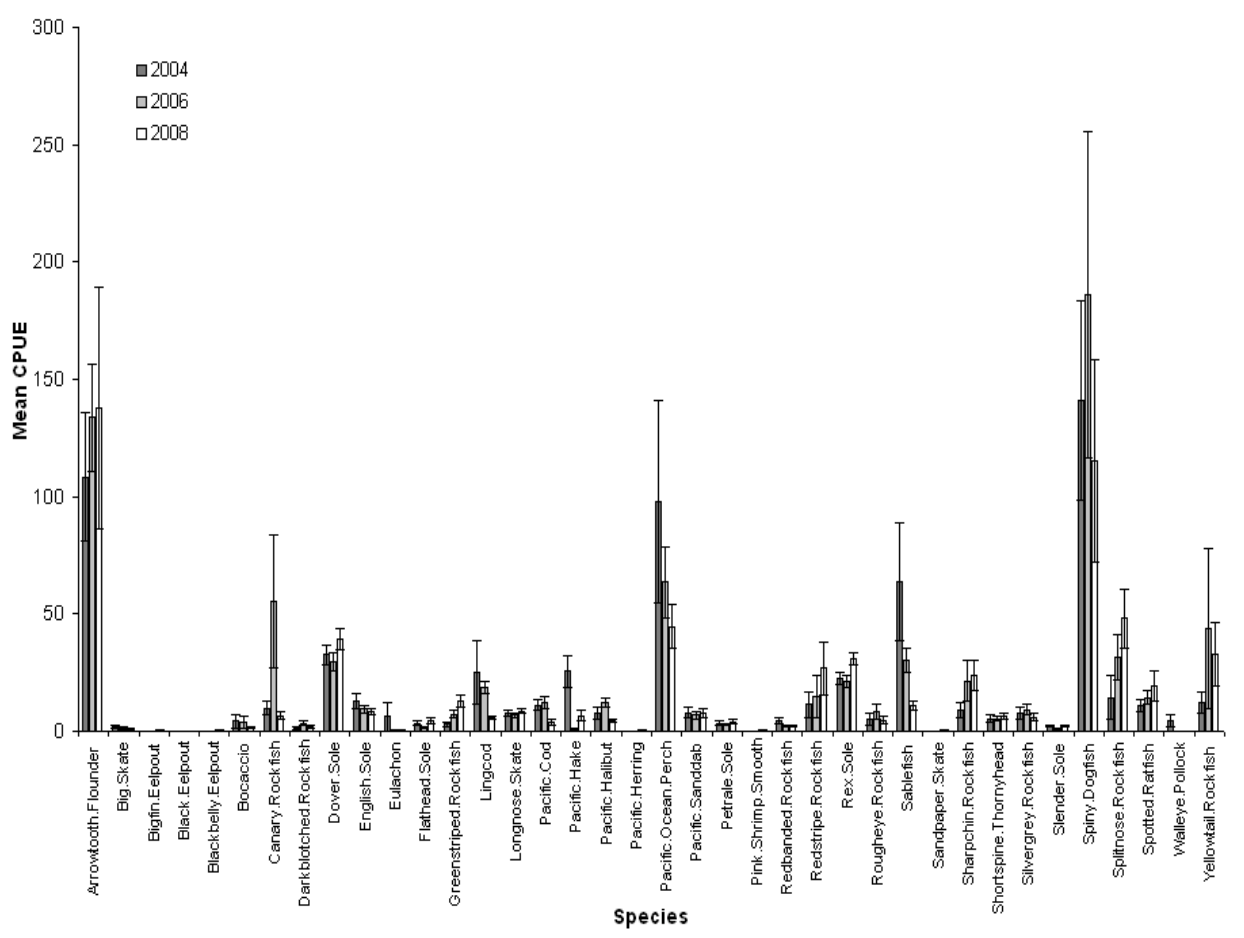

Fig. (2). Mean CPUE for each species in each of the survey years. Error bars show \pm 1 Standard Error.

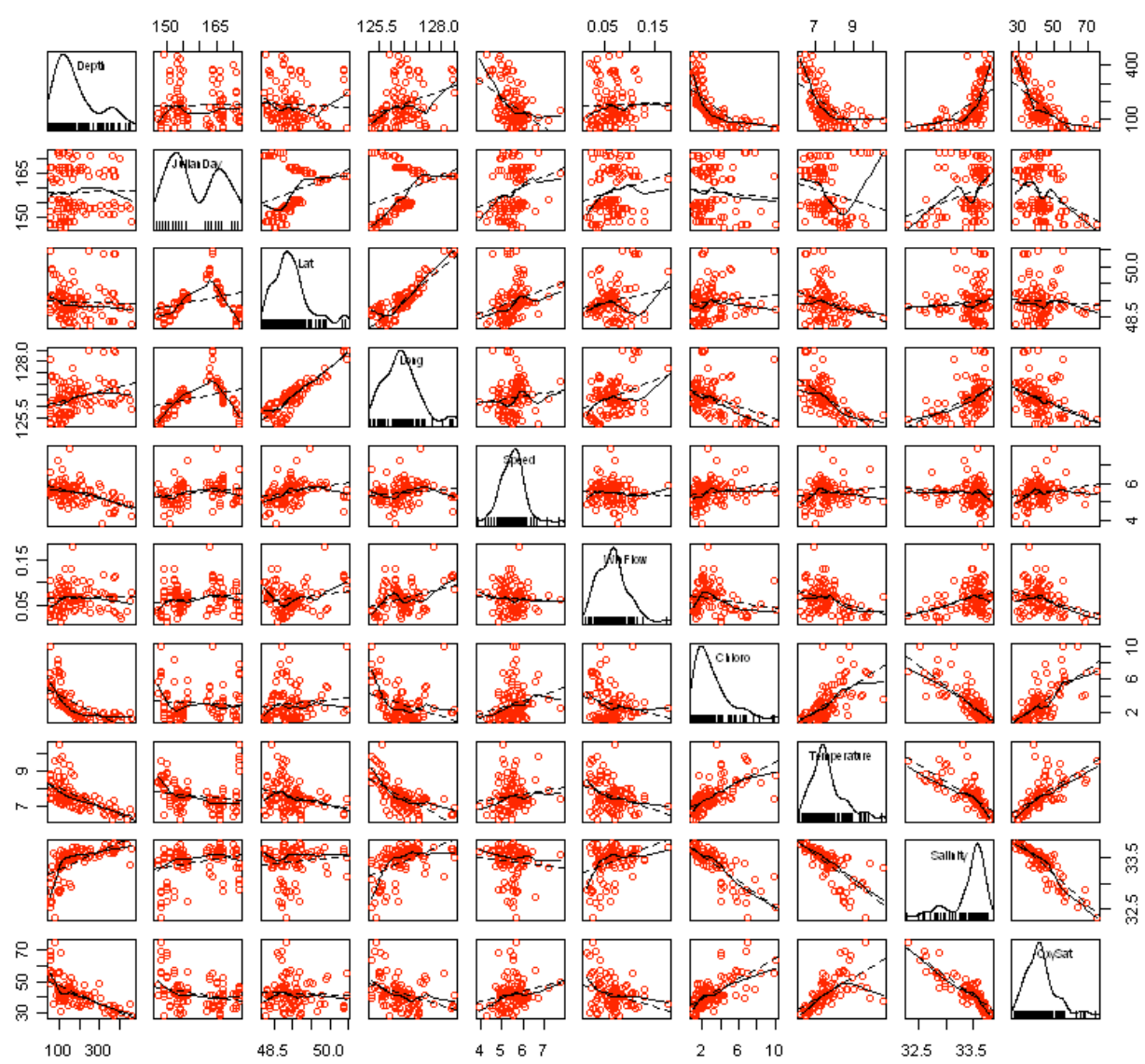

Fig. (3). A scatterplot matrix examining the relationships between environmental variables. There are correlations between many of the environmental variables and depth. Sites with missing values were removed from this analysis, and the remaining sites had an unexpected bimodal distribution with regards to the day of sampling; there is also a peculiar interaction between the JulianDay and positional variables. Any significant results based on the JulianDay variable may be an artefact of its unusual distribution. There is also a correlation between Speed and Depth, with trawls sampling deeper water moving more slowly. 
Table 3. Kendall's Tau Correlations between Environmental Variables $\left({ }^{*}: P<0.05,{ }^{\dagger}: P<0.01,{ }^{*}: P<0.001\right.$; Day: Julian Day, Lat: Latitude, Long: Longitude, Flow: Winter Flow Velocity, Chloro: Surface Chlorophyll Concentration, Temp: Temperature, Sal: Salinity, Oxy: Oxygen Saturation)

\begin{tabular}{|c|c|c|c|c|c|c|c|c|c|}
\hline Depth & 0.049 & -0.033 & $0.220^{*}$ & $-0.312^{+}$ & 0.015 & $-0.675^{*}$ & $-0.593^{\ddagger}$ & $0.583^{\star}$ & -0.564 \\
\hline Lat & & & $0.699^{*}$ & $0.102^{*}$ & $0.110^{\ddagger}$ & -0.021 & $-0.086^{\dagger}$ & 0.055 & -0.015 \\
\hline Flow & & & & & & $-0.096^{\dagger}$ & $-0.082 *$ & 0.006 & -0.045 \\
\hline Chloro & & & & & & & $0.531^{*}$ & $-0.518^{\ddagger}$ & $0.495^{*}$ \\
\hline Temp & & & & & & & & $-0.712^{+}$ & $0.681^{*}$ \\
\hline
\end{tabular}

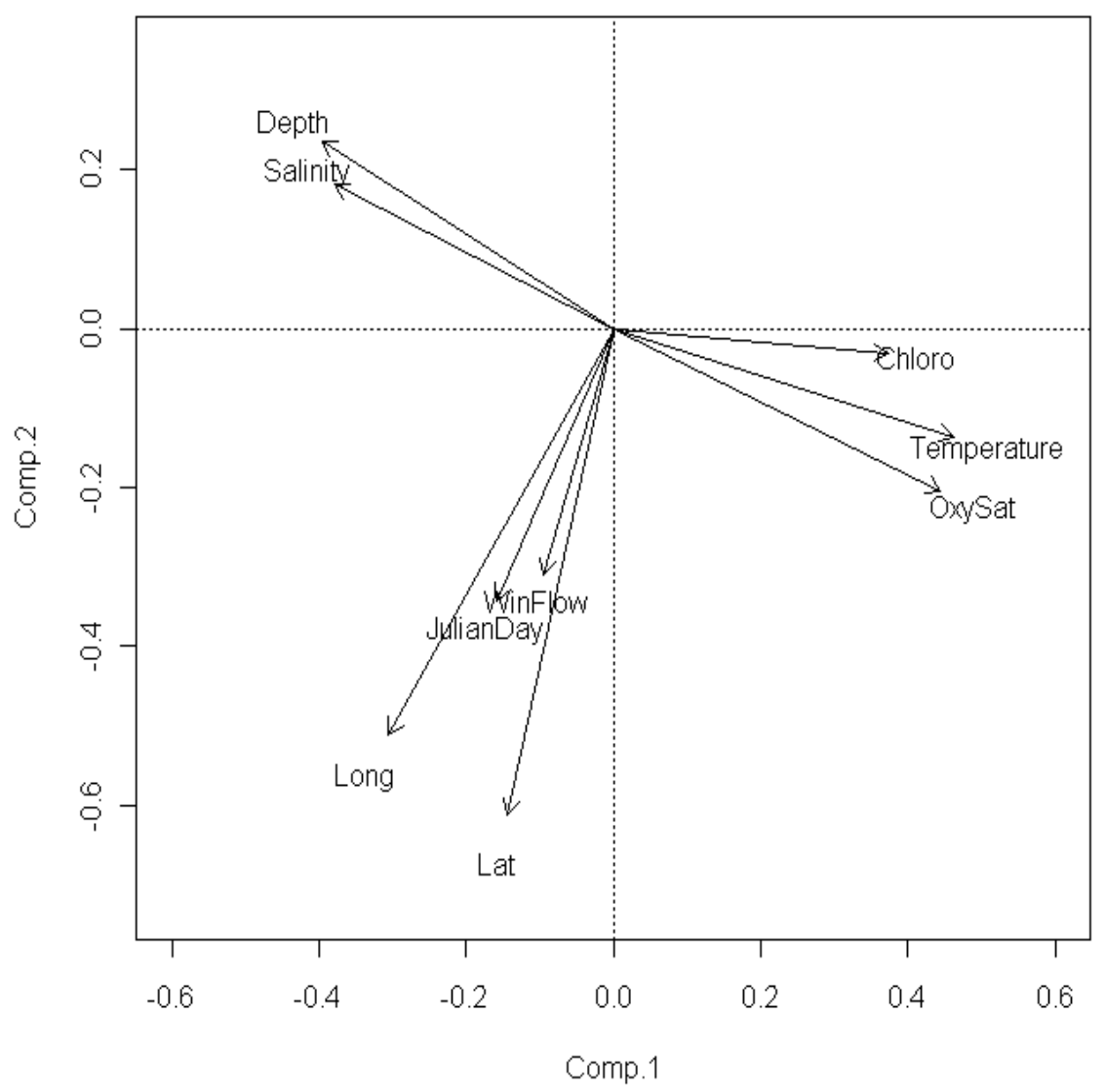

Fig. (4). Graphical results of a PCA of the environmental variables from Fig. (3), but with Speed removed to increase the number of available data points. There is a basic division between physical, biological, and chemical oceanographic variables along the first component axis, and physical and sampling variables along the second component axis, with strong correlation between the variables in each group.

into 4,5 , or 6 clusters did not produce any useful assemblages and any further divisions resulted in clusters of a single species. No natural divisions in assemblages were apparent in the results of the Canonical Analysis, so no further examination into clustering was performed. 


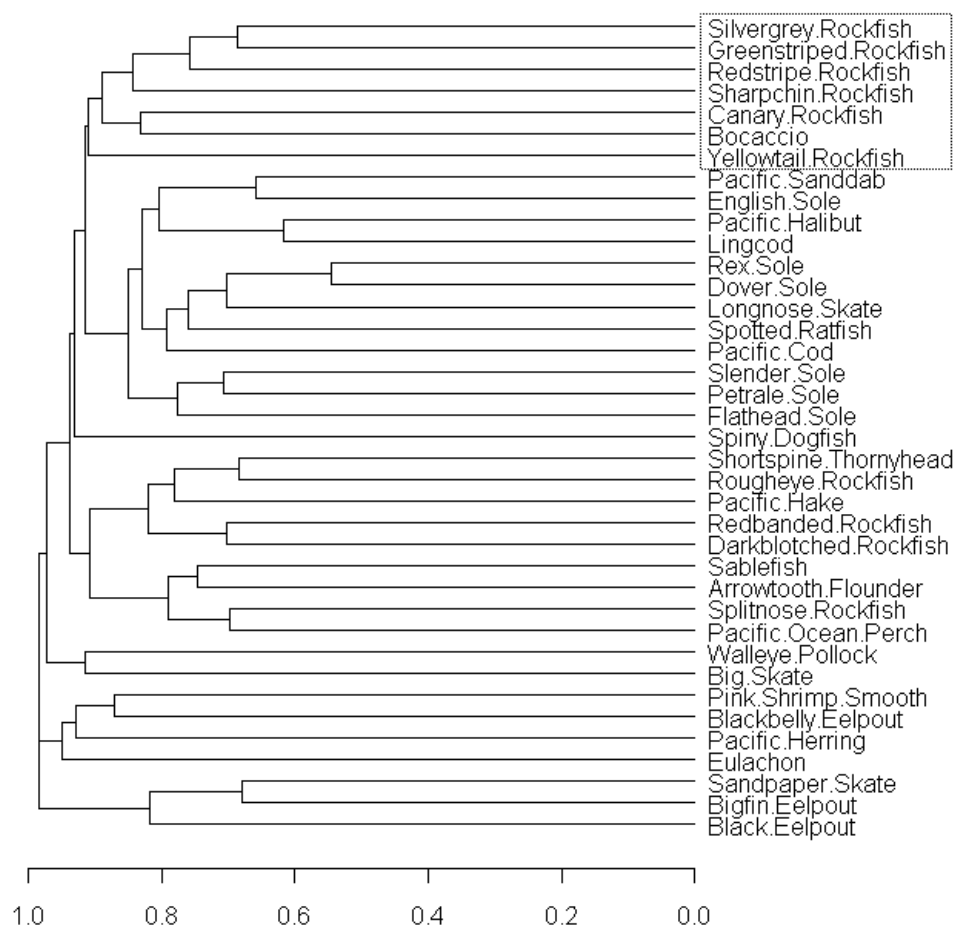

Fig. (5). Dendrogram showing clusters formed by Average linkage of a Bray-Curtis similarity matrix. The dashed box outlines a group of rockfishes that was also found through the Canonical Analysis (Fig. 6).

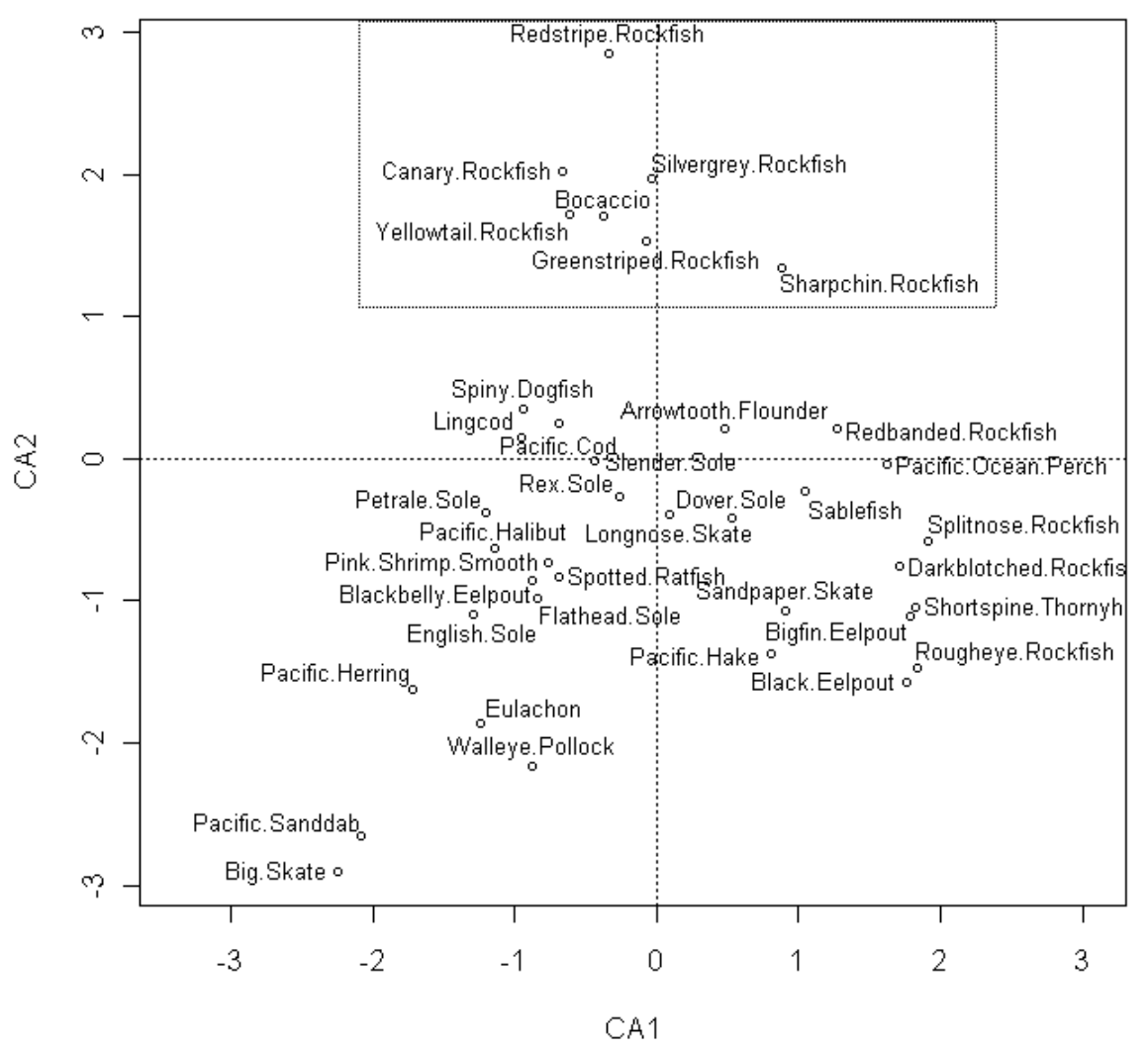

Fig. (6). Graphical results of a CA run to identify any natural groupings. The angle between the line segments connecting each species with the origin reveal co-occurrence, with closely associated species having acute angles, independent species having right angles, and negatively associated species having obtuse angles. The only notable grouping is the loose cluster of rockfishes outlined by the dashed box; this grouping is the same as was found by cluster analysis (Fig. 5). 
Table 4. Component Loadings of the Environmental Variables on the First Two Axes of the PCA and the Total Variance of the Component Axes

\begin{tabular}{|c|c|c|}
\hline Variable & Component 1 loading & Component 2 loading \\
\hline \hline Depth & -0.3965 & 0.2359 \\
\hline Julian day & -0.1588 & -0.3427 \\
\hline Latitude & -0.1439 & -0.6119 \\
\hline Longitude & -0.3057 & -0.5118 \\
\hline Winter Flow & -0.0943 & -0.3100 \\
\hline Chlorophyll & 0.3740 & -0.0316 \\
\hline Temperature & 0.4620 & -0.1367 \\
\hline Salinity & -0.3796 & 0.1814 \\
\hline $\begin{array}{c}\text { Oxygen } \\
\text { Saturation }\end{array}$ & 0.4439 & -0.2046 \\
\hline Total Variance & 3.961 & 2.074 \\
\hline
\end{tabular}

The variables showing the largest differences in distributions between species were depth (Fig. 7) and chlorophyll (Fig. 8). Minimal variations in distributions between species were evident in the oxygen saturation, salinity, and temperature variables, while the other variables showed no such variations.

The CCA run on the untransformed CPUE data as the community data set and the depth, Julian day, latitude, longitude, winter flow velocity, chlorophyll, temperature, salinity, and dissolved oxygen saturation variables as the environmental data set had high VIF values for latitude and longitude (51.65 and 70.74, respectively). Latitude was removed and the analysis was re-run. The VIF values for all variables in the resulting model were less than five, so there was no issue with correlation between environmental variables [21]. The ANOVA run on the environmental variables identified the significant variables as temperature $(P=0.074)$, chlorophyll $(P=0.002)$, and depth $(P=0.001)$. Following multiple backwards steps removing a single insignificant variable at a time, the model was left with only chlorophyll $(P=0.001)$ and depth $(P=0.001)$ as significant

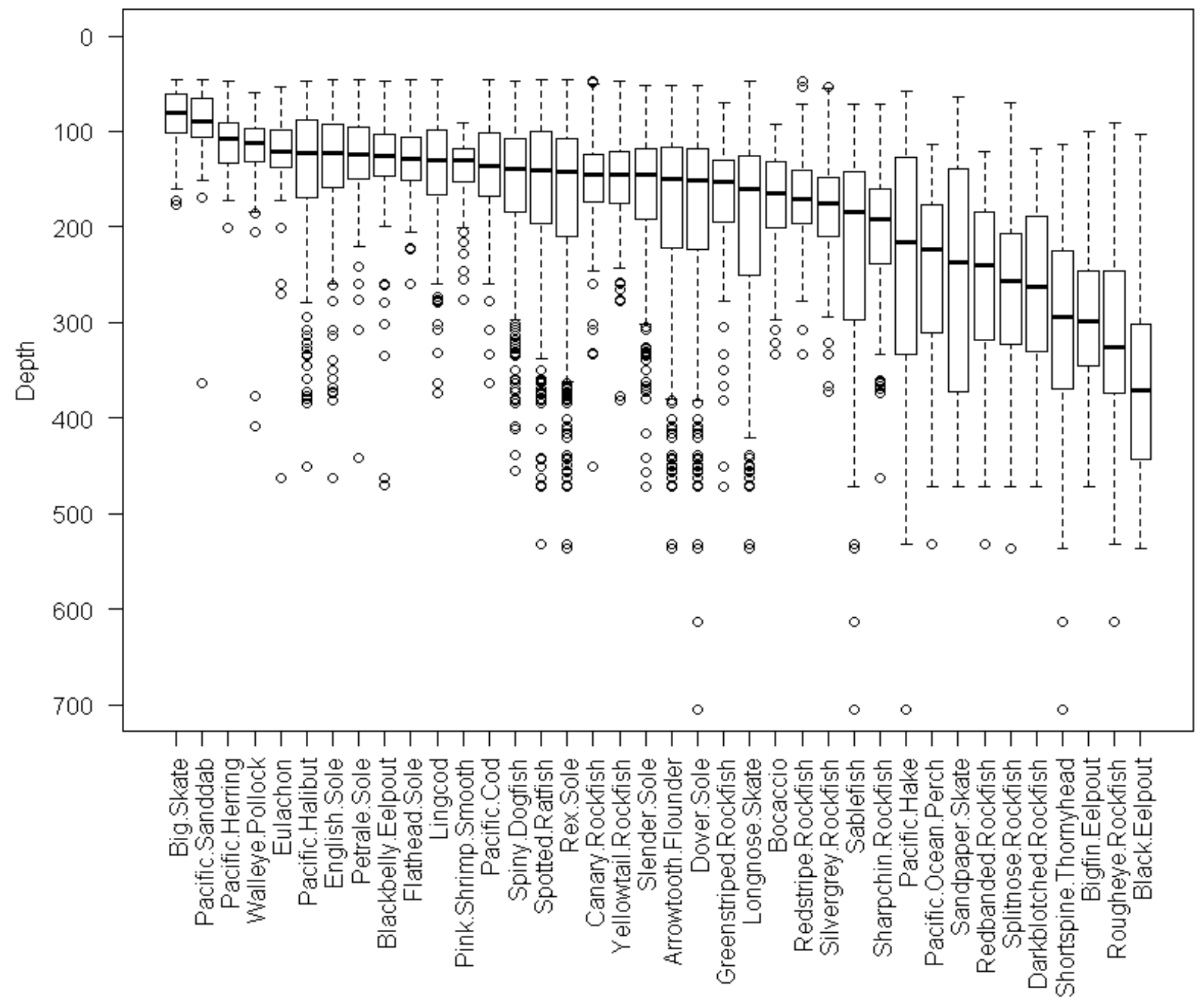

Fig. (7). Depth distribution for each species across all years, showing a gradual change in species composition from shallow to deeper water. Whiskers extend to the farthest point within 1.5 times the interquartile range from the edge of the box. 


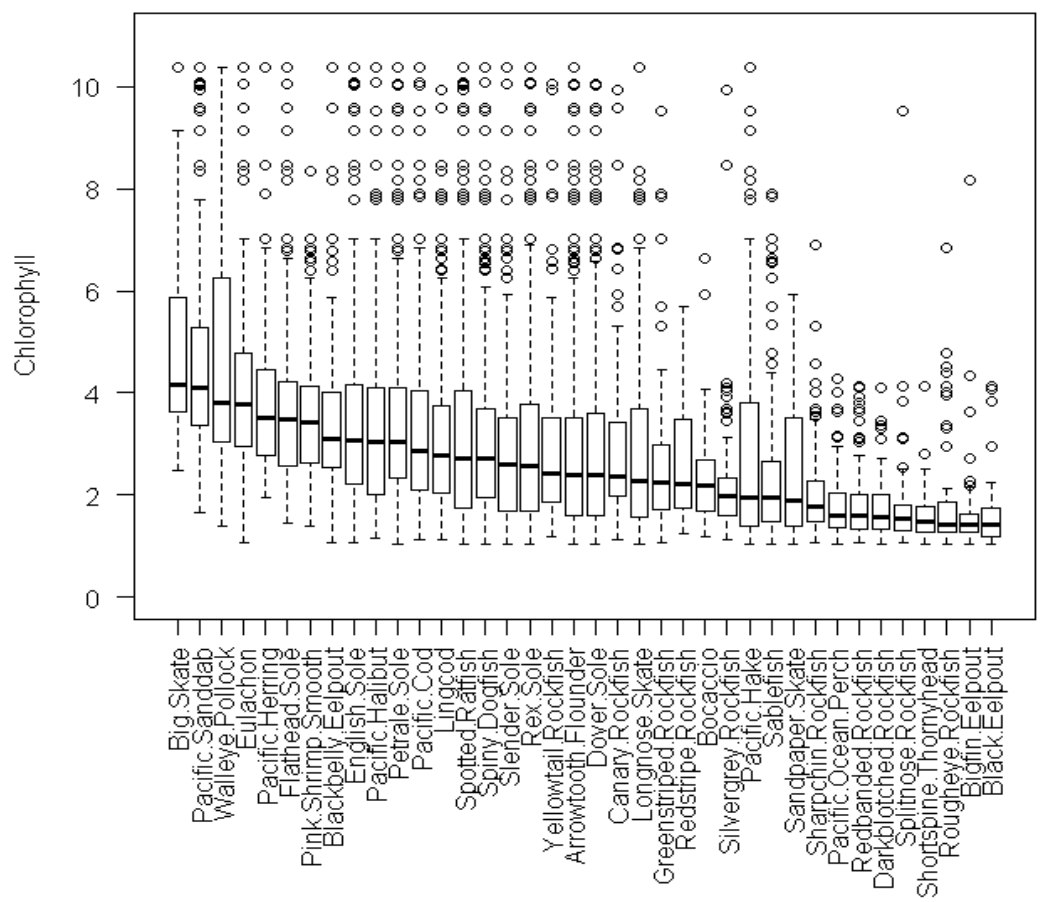

Fig. (8). Surface Chlorophyll distribution for each species across all years, showing a gradual change in species composition. Whiskers extend to the farthest point within 1.5 times the interquartile range from the edge of the box.

environmental variables (Fig. 9). Depth and chlorophyll appear to work as thresholds, wherein shallow dwelling species are limited by chlorophyll and deeper dwelling species are not. This is likely due to the high variation in chlorophyll concentration in shallow water and the high variation in depth in regions of low chlorophyll concentration.

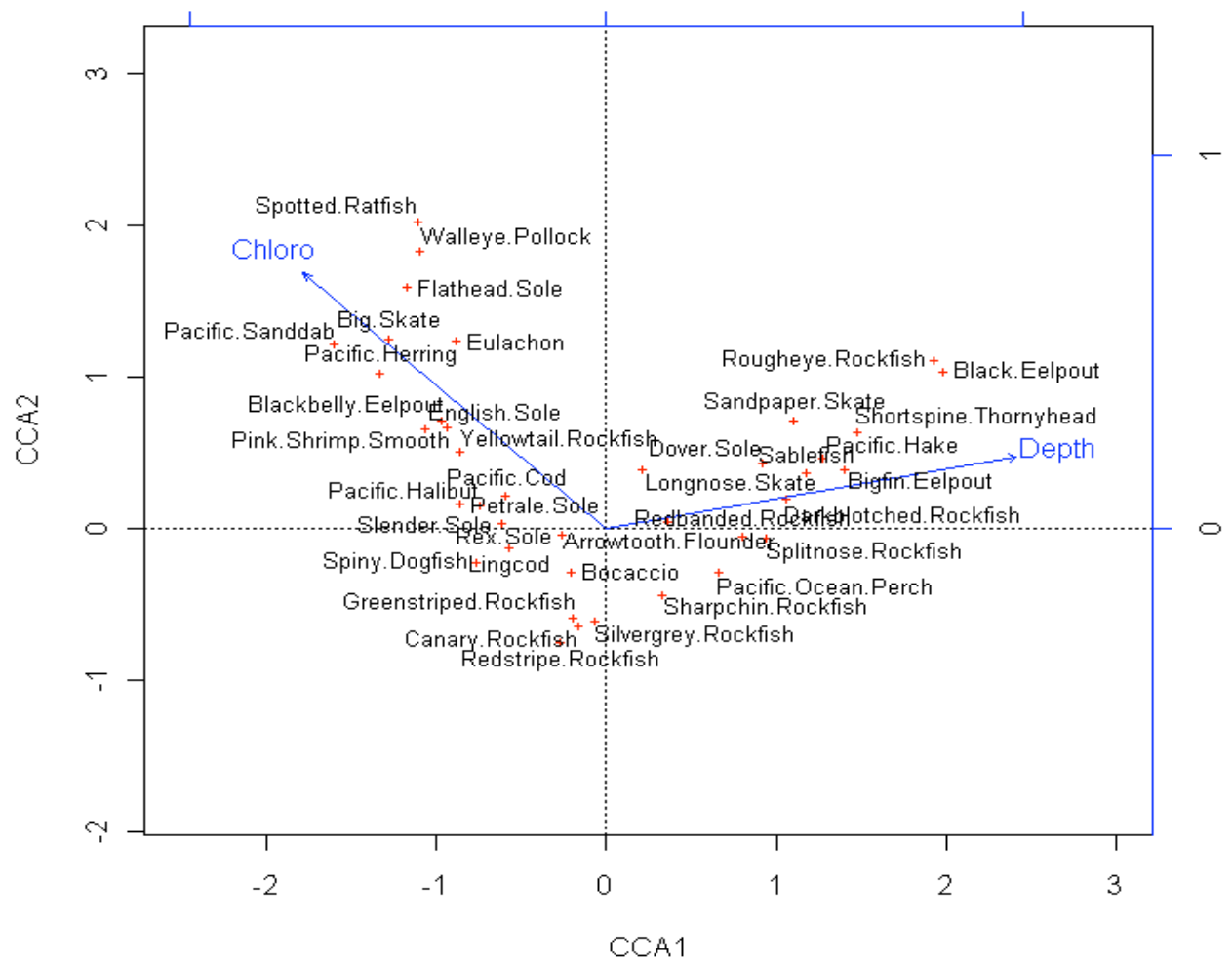

Fig. (9). Biplot of a CCA run on untransformed CPUE data, after manual backward steps, removing variables reported as insignificant by an ANOVA run on the model; only Chloro $(P=0.001)$ and Depth $(P=0.001)$ were significant. 


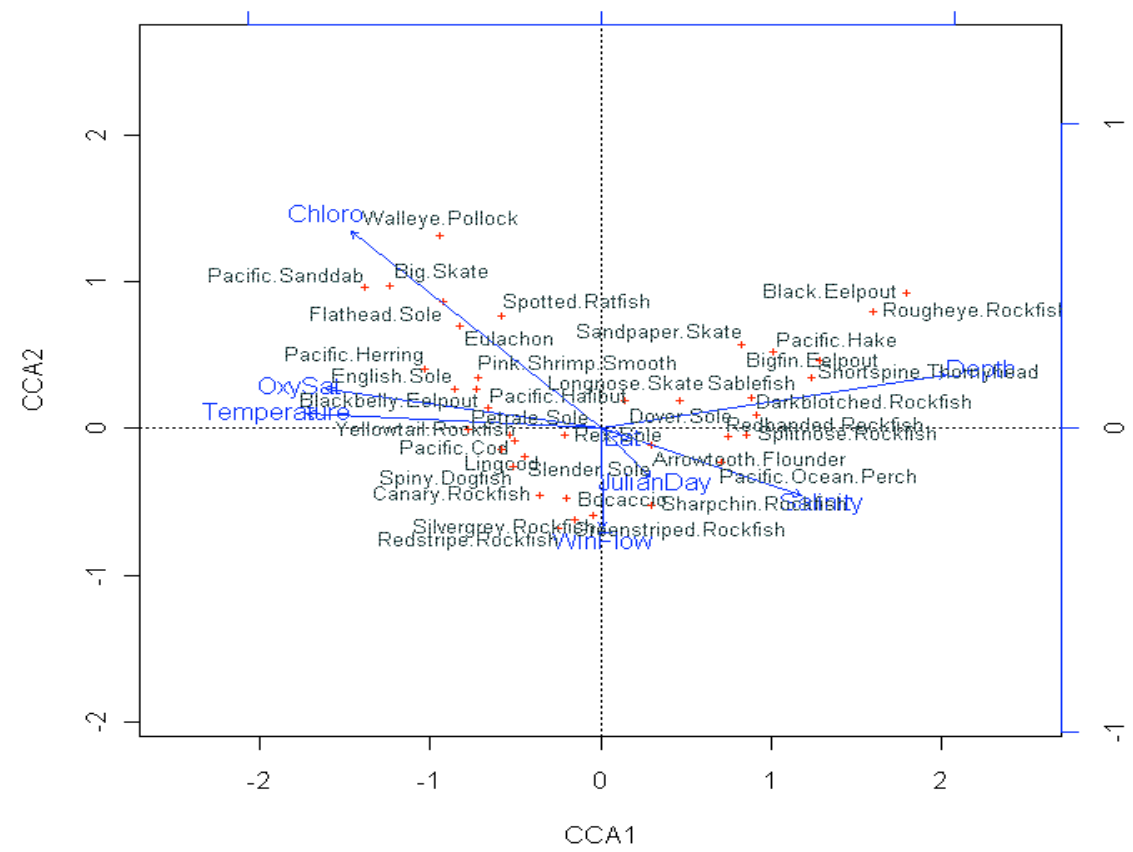

Fig. (10). Biplot of a CCA run on square root transformed CPUE data, showing the trends of all environmental variables except Speed (removed because of gaps) and Longitude (removed due to its high VIF). All variables included were reported as significant by an ANOVA run on the model (Depth: $P=0.001$, JulianDay: $P=0.032$, Lat: $P=0.012$, WinFlow: $P=0.019$, Chloro: $P=0.001$, Temperature: $P=0.002$, Salinity: $P=0.003$, OxySat: $P=0.004)$.

The CCA run on the square-root transformed CPUE data as the community data set and the depth, Julian day, latitude, longitude, winter flow velocity, chlorophyll, temperature, salinity, and oxygen saturation variables as the environ- mental data set had high VIF values for latitude and longitude (44.93 and 61.94, respectively). Longitude was removed and the analysis was re-run (Fig. 10). All variables included were reported as significant by the ANOVA run on

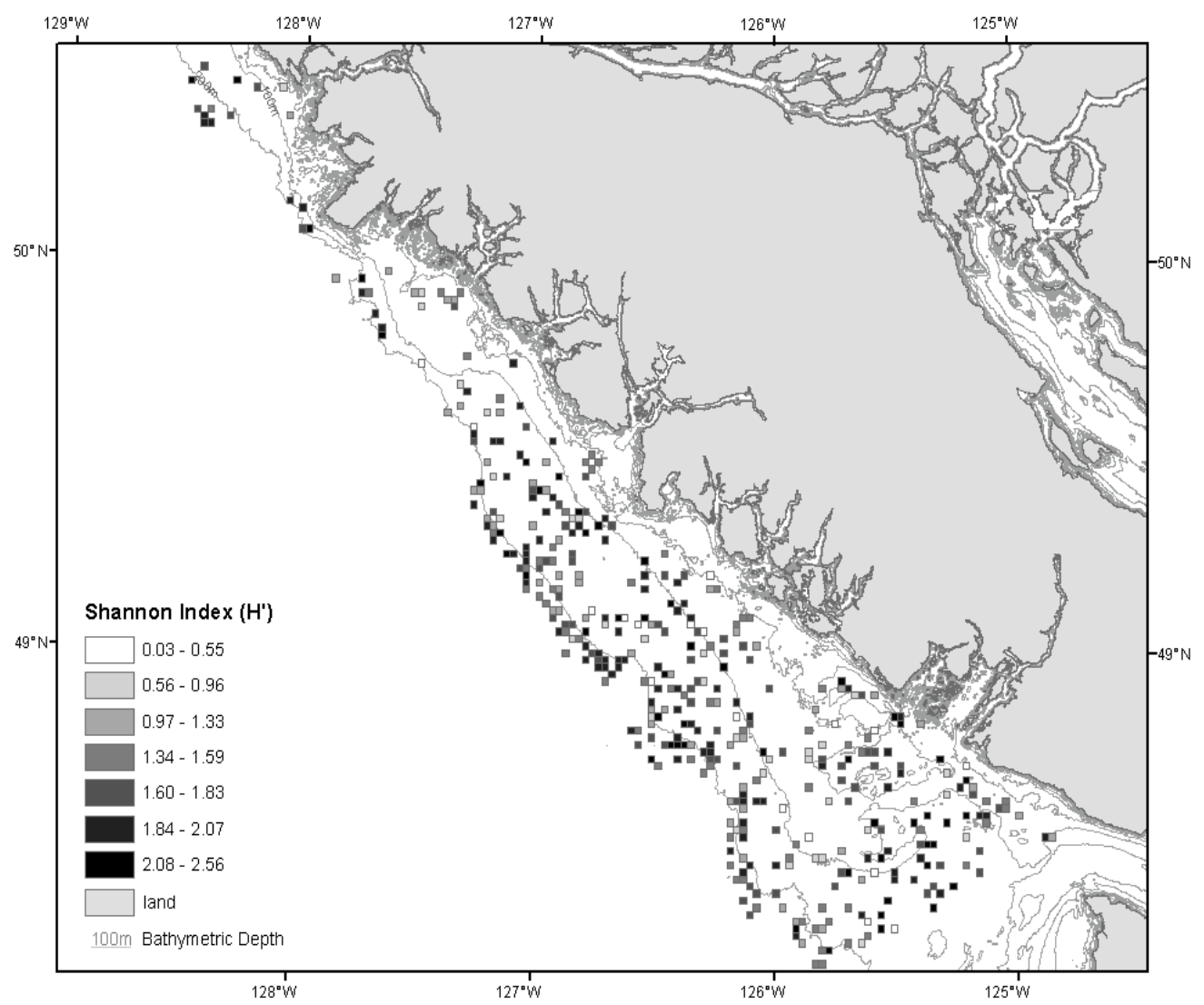

Fig. (11). Map of the species diversity (Shannon Index, H') of each trawl showing no obvious latitudinal, longitudinal, or bathymetric trends. 


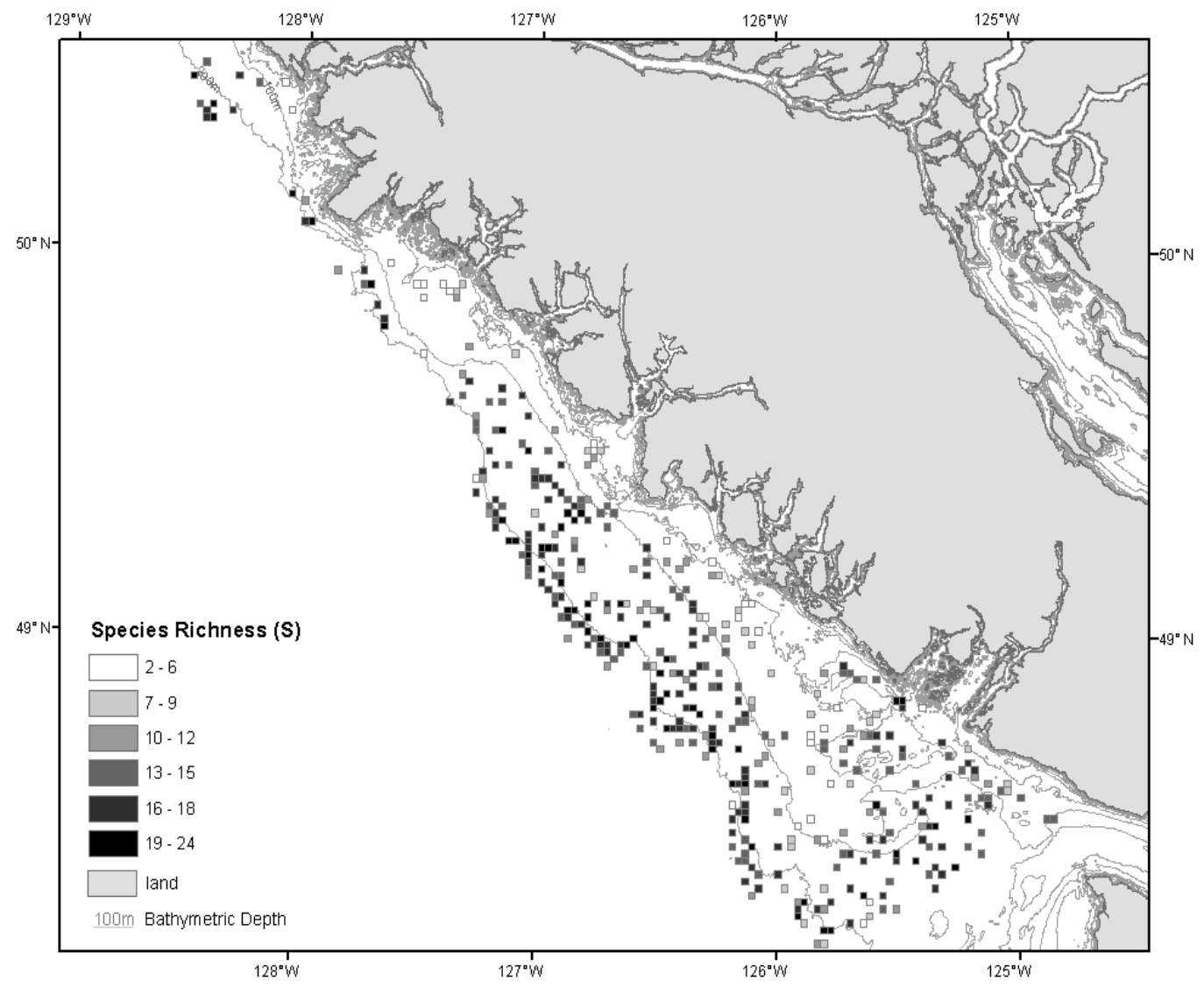

Fig. (12). Map of the species richness (S) of each trawl showing no obvious latitudinal or longitudinal trends, but a slight increase in species richness with increasing depth.

the model (Depth: $P=0.001$, JulianDay: $P=0.032$, Lat: $P=$ 0.012, WinFlow: $P=0.019$, Chloro: $P=0.001$, Temperature: $P=0.002$, Salinity: $P=0.003$, OxySat: $P=0.004$ ). However, upon visual inspection, the dominant variables still appeared to be depth (with its negative correlation with oxygen saturation and temperature), and chlorophyll.

There were no latitudinal or longitudinal trends in species diversity (Fig. 11) or species richness (Fig. 12). Species richness decreased with an increase in chlorophyll, but this response varied with depth (Species Richness $=18.366-$ 0.027 Depth -2.340 Chloro +0.019 Chloro*Depth, Table 5). There were trends in the positions of the dominant species, with many species being dominant either in one

Table 5. ANOVA Table from a Linear Model Showing that Species Richness Varies with Chlorophyll Differently at Different Depths (Species Richness $=18.366$ - 0.027 Depth - 2.340 Chloro + 0.019 Chloro*Depth, $R^{2}=0.2416$ )

\begin{tabular}{|c|c|c|c|c|c|}
\hline & df & SS & MS & $\boldsymbol{F}$ & $\boldsymbol{P}$ \\
\hline \hline Depth & 1 & 392.0 & 392.0 & 26.989 & $3.145 \times 10^{-07}$ \\
\hline Chloro & 1 & 618.8 & 618.8 & 42.604 & $1.862 \times 10^{-10}$ \\
\hline Depth:Chloro & 1 & 1011.4 & 1011.4 & 69.635 & $9.455 \times 10^{-16}$ \\
\hline Residuals & 437 & 6346.9 & 14.5 & & \\
\hline
\end{tabular}

small region (e.g. Spotted Ratfish near the mouth of Barkley Sound), or in a band of a specific depth range (e.g. Pacific Sanddab near shore, and Spiny Dogfish between 100-200 m) (Fig. 13).

\section{DISCUSSION}

Recently, much value has been placed on determining fish species assemblages in preparation for a potential shift to ecosystem-based fisheries management $[9,10]$. Many of the studies in this field are based in areas of extreme natural environmental divisions, e.g. the arctic/subarctic temperature division [16], the contrast between estuarine and shelf communities $[13,29]$, or the difference between communities on and off a seamount [9]. When these studies occur in regions of less extreme gradients, changes in assemblage structure tend to be more gradual $[10,18]$. We found that the identities of the groundfish species off the west coast of Vancouver Island present at any point along environmental gradients change so subtly that it was impossible to delineate assemblages with any degree of certainty. This finding is consistent with niche theory, which suggests that no two species with the same environmental needs can permanently co-exist [30]. Further, there were no gaps in species distributions large enough to suggest any natural divisions, excepting the single group of rockfishes identified through the Average Bray-Curtis dendrogram and the Canonical Analysis. Otherwise, species identity appeared to be mainly determined by depth until a shallow threshold was reached, 


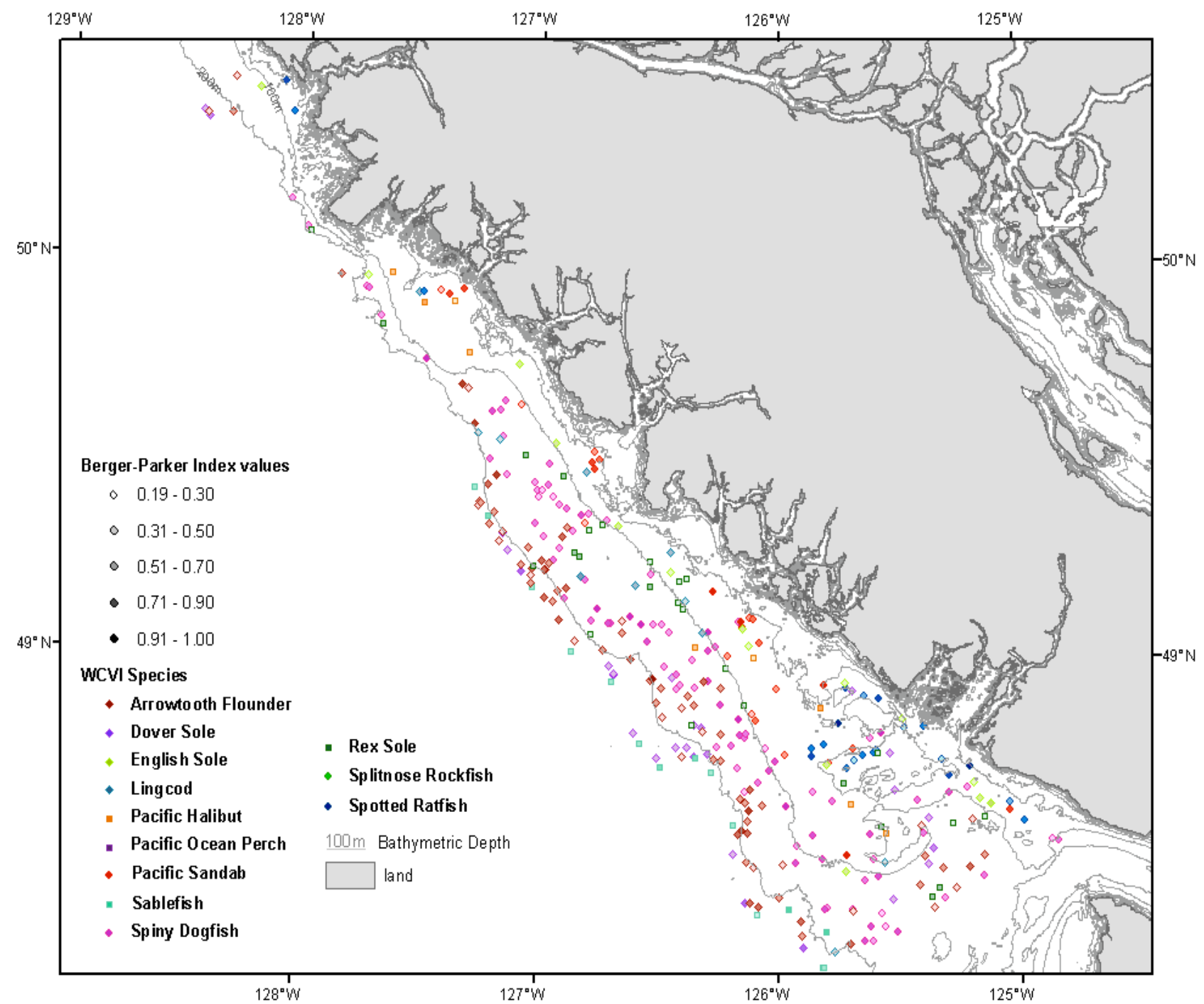

Fig. (13). Map showing the dominant species at each site. The saturation of each point represents the Berger-Parker Dominance index (i.e. where the dominant species represents a large portion of the total CPUE, the point is more opaque). For clarity, not all dominant species are shown; species were selected that were dominant frequently and that appeared to be dominant in specific regions or bands (e.g. Spotted Ratfish were dominant near the mouth of Barkley Sound; Pacific Sanddab were dominant near shore; Spiny Dogfish were dominant between 100-200 m; Arrowtooth Flounder were dominant along the $200 \mathrm{~m}$ depth contour). Excluded species did not show the same regionalization or banding.

then by chlorophyll concentration at shallow depths. Primary production is an important determinant of overall biomass in the region [2], so it is interesting that some species appear to thrive in areas of low chlorophyll concentration. However, this does not mean that the biomass of these species would not increase with an overall increase in primary productivity in the region as these species may benefit indirectly. Since our chlorophyll data represented an average over time, it was not possible to determine if varying chlorophyll concentrations between years were reflected in shifts in the proportional abundance of different species. Depth has been shown to be important in determining species composition $[9,29$, 31 ], though it is often viewed as a proxy for other variables, such as temperature, salinity, dissolved oxygen, and light [10]. We found that the inclusion of temperature, salinity, or dissolved oxygen only provided additional explanatory power when compared to the square-root transformed CPUE data, suggesting that species identity is generally controlled by depth and chlorophyll, but that other oceanographic conditions may have small-scale or highly localized effects. Since these variables are strongly correlated with depth, it is difficult to separate the effects of each variable.

Species assemblages have also been studied for the purpose of suggesting essential fish habitat [15], by identifying groups that are tightly restricted along some environmental gradient. Just as indicator species serve as a measure of community health, indicator assemblages may provide insight into ecosystem health. It may be easier to define areas to protect by identifying the ecological characteristics that are unique and important to such assemblages, rather than looking at the needs of individual species. Assemblages with narrower niches may require more stringent management to prevent extirpation. The group of rockfishes we identified may be an assemblage worth examining for this purpose. Although its component species had unremarkable 
distributions with regards to chlorophyll concentration and depth, they did appear to be located at the apex of the winter flow velocity gradient. Winter flow velocity may be acting here as a proxy for substrate type, with high velocity possibly indicating a rocky seafloor. Depending on the rarity and biological importance of these rocky areas, they may be worth considering for protection. Future survey trawls should be accompanied by local substrate data (e.g. from side-scan sonar), which may allow for easier identification of assemblages. It may also be valuable to consider the abundance of structural benthic invertebrates within each trawl as an environmental variable, as some fish show preferential use of highly structured habitats [32].

Another purpose for defining assemblages is to determine community changes in response to climate change $[4,16]$, or other sources of inter-annual variation [29]. Mobile species are able to escape unfavourable conditions created by changes in climate, while stationary species are not [4]. Therefore, changes in assemblages could be due to the dispersal of more mobile species away from changing oceanic conditions. Within our samples, there was minimal variation in the CPUE of each species between the three sampled years, particularly when compared with the variation in CPUE between species. However, it is likely that our sampling time frame was too narrow to detect any significant compositional shifts, which may occur over a longer term. In this case, our study will provide a baseline against which future studies can be compared. Long-term studies of the species composition in this region will need to account for the short-term variations caused by the seasonal movement of individual species [19]. Since the surveys occur at similar dates each year, this will only be an issue if the seasonal climatic shifts happen at a relatively different time (e.g. if the spring transition is early or late one year). Another potential confounder is the difference in distributions of resident and facultative species [30]. Facultative species tend to be eurytopic and make it difficult to distinguish between assemblages as they may be present in more than one [9]. They may also not occur in the same location in different years for reasons other than shifts in environmental conditions. An example facultative species from our study is Spiny Dogfish, which is known to migrate out of our study region [33].

Our finding that species richness increases with depth and decreases with increasing chlorophyll concentration is contrary to the expectation of decreasing species richness with increasing depth [34-36]. This may be an artefact of our sampling regime, which targets larger-bodied species. Since fish body size tends to increase with depth [31], our samples may not accurately represent the richness of small-bodied species present at shallow depths. Further, the limitation of the species list to the 38 most prevalent species in terms of biomass and catch rate may exclude many rare species. If these excluded species were primarily small-bodied and shallow-dwelling, their inclusion could increase the richness at shallow depths. Our finding that species tend to be dominant in zones or pockets is consistent with niche theory whereby species distribution is unimodal with respect to environmental and resource needs and the maxima of multiple species should not overlap [30]. The zones aligned with depth are consistent with our other results of this being an important factor in species identity; however, the pockets of dominance represent a patchiness that our data are unable to explain, perhaps reflecting patchiness in the substrate.

The concept of assemblages has an interesting ramification in species recovery research: if a population of a single species is reduced disproportionately with respect to the other members of its assemblage, is it more likely that the population will recover or that the other members of the assemblage will expand their distributions into the newly available niche space? It is worth noting that species assemblage research tells us nothing of community structure, i.e. we can determine which species co-occur, but not how they interact. Knowledge of these interactions would likely be necessary in order to answer the question about recovery. Species assemblage research provides a valuable function in directing future research on community interactions by suggesting groups of species that are likely to interact. One approach to this community research might be to map the theoretical distribution for each species and to compare the expected assemblage to the sampled one. This might provide insight into the interspecies interactions that lead to discrepancies between the fundamental and realized niches.

A previous study conducted off the west coast of North America recognized that the boundaries between assemblages were unclear, but still defined assemblages based on the species present at repeatedly sampled stations [18]. We have decided that defining discrete assemblages where they do not exist could prove detrimental to fisheries management; since our analyses suggest that species identity varies continuously and not discretely, we opted not to attempt to define assemblages of the groundfish off the west coast of Vancouver Island. If the goal of ecosystem management is to protect the proper functioning of communities [10], then it is not necessary to define discrete assemblages. Forcing species into artificial groupings for the purpose of managing fisheries may prove detrimental in two situations: $i$ ) when a species has a smaller distribution range than that of its assemblage, fisheries operating within the area defined by the assemblage range but outside of the species range will not catch the target species; and ii) when species occur in multiple assemblages, but are only defined as contributing to one (as in [29]), fisheries will catch species that are not part of their target assemblage. Both situations would represent a failing of ecosystem management to minimize the impacts of fishing while maximizing yields. An alternative could be to determine the distributions of individual species and to prescribe trawl locations that maximize the theoretical catch to bycatch ratio of the single or multiple target species. The output of such a system could be maps clearly identifying regions that will theoretically yield acceptable catch to bycatch ratios. Although temporal variations would still need to be considered, setting up a quota system limiting total catch (including bycatch) would allow fisheries managers to directly assess and minimize the environmental impacts of fishing while maximizing yields of target species.

\section{ACKNOWLEDGEMENTS}

Funding for the primary author was provided by Fisheries and Oceans Canada under the Ecosystem Research Initiative. We wish to acknowledge Sarah Thompson for her 
GIS work and for producing the maps, and an anonymous reviewer for his suggestions.

\section{REFERENCES}

[1] McFarlane GA, Ware DM, Thomson RE, Mackas DL, Robinson CLK. Physical, biological and fisheries oceanography of a large ecosystem (west coast of Vancouver Island) and implications for management. Oceanologica Acta 1997; 20(1): 191-200.

[2] Ware DM, Thomson RE. Bottom-up ecosystem trophic dynamics determine fish production in the northeast Pacific. Science 2005; 308: 1280-4.

[3] Attril MJ, Power M. Climatic influence on a marine fish assemblage. Nature 2002; 417: 275-8

[4] Nye JA, Link JS, Hare JA, Overholtz WJ. Changing spatial distribution of fish stocks in relation to climate and population size on the Northeast United States continental shelf. Mar Ecol Prog Ser 2009; 393: 111-29.

[5] Harley CDG, Hughes AR, Hultgren KM, et al. The impacts of climate change in coastal marine systems. Ecol Lett 2006; 9: 22841.

[6] Cury PM. Tuning the ecoscope for the ecosystem approach to fisheries. Mar Ecol Prog Ser 2004; 274: 272-5.

[7] Ban NC, Vincent ACJ. Beyond marine reserves: exploring the approach of selecting areas where fishing is permitted, rather than prohibited. Plos ONE 2009; 4(7): e6258.

[8] Pauly D, Lourdes Palomares M, Froese R, et al. Fishing down Canadian aquatic food webs. Can J Fish Aquat Sci 2001; 58: 51-62.

[9] Sanchez F, Serrano A, Parra S, Ballesteros M, Cartes JE. Habitat characteristics as determinant of the structure and spatial distribution of epibenthic and demersal communities of Le Danois Bank (Cantabrian Sea, N. Spain). J Mar Syst 2008; 72: 64-86.

[10] Tolimieri N, Levin PS. Assemblage structure of eastern Pacific groundfishes on the U.S. continental slope in relation to physical and environmental variables. Trans Am Fish Soc 2006; 135: 31732.

[11] Frid CLJ, Paramor OAL, Scott CL. Ecosystem-based management of fisheries: is science limiting? ICES J Mar Sci 2006; 63: 156772 .

[12] Lotze HK. Repetitive history of resource depletion and mismanagement: the need for a shift in perspective. Mar Ecol Prog Ser 2004; 274: 282-5.

[13] Catalán AI, Jiménez MT, Alconchel JI, Prieto L, Muñoz JL. Spatial and temporal changes of coastal demersal assemblages in the Gulf of Cadiz (SW Spain) in relation to environmental conditions. DeepSea Res II 2006; 53: 1402-19.

[14] Prista N, Vasconcelos RP, Costa MJ, Cabral H. The demersal fish assemblage of the coastal area adjacent to the Tagus estuary (Portugal): relationships with environmental conditions. Oceanologica Acta 2003; 26: 525-36.

[15] Auster PJ, Joy K, Valentine PC. Fish species and community distributions as proxies for seafloor habitat distributions: the Stellwagen Bank National Marine Sanctuary example (Northwest Atlantic, Gulf of Maine). Eniron Biol Fishes 2001; 60: 331-46.

[16] Mueter FJ, Litzow MA. Sea ice retreat alters the biogeography of the Bering Sea continental shelf. Ecol Appl 2008; 18(2): 309-20.

[17] Sissenwine M, Murawski S. Moving beyond 'intelligent tinkering': advancing to and ecosystem approach to fisheries. Mar Ecol Prog Ser 2004; $274: 291-5$
[18] Zimmerman M. Benthic fish and invertebrate assemblages within the National Marine Fisheries Service US west coast triennial bottom trawl survey. Continental Shelf Res 2006; 26: 1005-27.

[19] Workman GD, Olsen N, Fargo J, Stanley RD. West Coast Vancouver Island groundfish bottom trawl survey, R/V WE RICKER, May 25th to June 10th, 2004. Can Manuscr Rep Fish Aquat Sci 2008; 2826: viii +64 p.

[20] R Development Core Team. R: a language and environment for statistical computing. R Foundation for Statistical Computing: Vienna, Austria. ISBN 3-900051-07-0. version 2.9.0. 2009; Available from: http://www.R-project.org

[21] Kindt R, Coe R. Tree diversity analysis. A manual and software for common statistical methods for ecological and biodiversity studies Nairobi: World Agroforestry Centre (ICRAF) 2005.

[22] Oksanen J, Kindt R, Legendre P, et al. Vegan: community ecology package. R package version 1.15-2. 2009; Available from: http:// CRAN.R-project.org/package $=$ vegan

[23] Swayne D, Lang DT, Cook D, Buja A. GGobi. Version 2.1.8. 2008; Available from: http://www.ggobi.org

[24] Pielou EC. Mathematical ecology. New York: John Wiley \& Sons 1977.

[25] Clarke KR, Somerfield PJ, Chapman MG. On resemblance measures for ecological studies, including taxonomic dissimilarities and a zero-adjusted Bray-Curtis coefficient for denuded assemblages. J Exp Mar Biol Ecol 2006; 330: 55-80.

[26] ter Braak CJF, Verdonschot PFM. Canonical correspondence analysis and related multivariate methods in aquatic ecology. Aquat Sci 1995; 5(4): 1-35.

[27] Clarke KR, Chapman MG, Somerfield PJ, Needham HR Dispersion-based weighting of species counts in assemblage analyses. Mar Ecol Prog Ser 2006; 320: 11-27.

[28] Clarke KR, Warwick RM. Change in marine communities: an approach to statistical analysis and interpretation, $2^{\text {nd }}$ ed. Diversity measures, dominance curves and other graphical analyses. PRIMER-E: Plymouth 2001

[29] Juareguizar AJ, Menni R, Lasta C, Guerrero R. Fish assemblages of the northern Argentine coastal system: spatial patterns and their temporal variations. Fish Oceanogr 2006; 15(4): 326-44.

[30] Watkins AJ, Wilson JB. Fine-scale community structure of lawns. J Ecol 1992; 80(1): 15-24

[31] Haedrich RL, Rowe GT, Polloni PT. The megabenthic fauna in the deep sea south of New England, USA. Mar Biol 1980; 57: 165-79.

[32] Tissot BN, Yoklavich MM, Love MS, York K, Amend M. Benthic invertebrates that form habitat on deep banks off southern California, with special reference to deep sea coral. Fish Bull 2006 104(2): 167-81.

[33] McFarlane GA, King JR. Migration patterns of spiny dogfish (Squalus acanthis) in the North Pacific Ocean. Fish Bull 2003; 101(2): 358-67.

[34] Leathwick JR, Elith J, Francis MP, Hastie T, Taylor, P. Variation in demersal fish species richness in the oceans surrounding New Zealand: an analysis using boosted regression trees. Mar Ecol Prog Ser 2005; 321: 267-81.

[35] Mittelbach GG, Steiner CF, Scheiner SM, et al. What is the observed relationship between species richness and productivity? Ecology 2001; 82(9): 2381-96.

[36] Tolimieri N. Patterns in species richness, species density, and evenness in groundfish assemblages on the continental slope of the U.S. Pacific coast. Environ Biol Fish 2007; 78: 241-56. 